\title{
Redox-responsive self-healing materials formed from host-guest polymers
}

\author{
Masaki Nakahata', Yoshinori Takashima', Hiroyasu Yamaguchi \& Akira Harada
}

Expanding the useful lifespan of materials is becoming highly desirable, and self-healing and self-repairing materials may become valuable commodities. The formation of supramolecular materials through host-guest interactions is a powerful method to create non-conventional materials. Here we report the formation of supramolecular hydrogels and their redox-responsive and self-healing properties due to host-guest interactions. We employ cyclodextrin (CD) as a host molecule because it is environmentally benign and has diverse applications. A transparent supramolecular hydrogel quickly forms upon mixing poly (acrylic acid) ( $p A A$ ) possessing $\beta-C D$ as a host polymer with $\mathrm{pAA}$ possessing ferrocene as a guest polymer. Redox stimuli induce a sol-gel phase transition in the supramolecular hydrogel and can control self-healing properties such as re-adhesion between cut surfaces. 
$\mathrm{H}$ igh-performance materials such as stimulus-responsive and maintenance-free self-healing materials ${ }^{1-9}$ have attracted much attention due to modern environmental and energy concerns. Recently developed functional soft materials possessing switching, self-healing and self-repairing features are expected to have diverse applications (for example, in architectural materials and external coatings). Some research groups have attempted to create switching soft materials such as remotely actuated nanomaterials $^{10-14}$, artificial molecular muscles ${ }^{15,16}$, drug-delivery systems ${ }^{17,18}$, biosensors and shape memory materials. Although there are previous examples of supramolecular hydrogels ${ }^{19}$ where a sol-gel phase transition occurs using heat ${ }^{20}, \mathrm{pH}^{21}$, light ${ }^{22-25}$ or redox ${ }^{26-32}$ as a stimulus, it is difficult to create multi-functional soft materials owing to complicated designs and syntheses. Hence, redox stimulus-responsive self-healing materials have yet to be reported.

Previously, we have reported stimulus-responsive supramolecular materials possessing host and guest polymers ${ }^{33-35}$. Supramolecular materials consisting of host and guest polymers have unique features due to selective complementary interactions. Host-guest interactions are versatile, and can be used to prepare supramolecular materials, which have easily tuned switching efficiencies and functions. Self-healing and self-repairing properties may be achieved using supramolecular materials that consist of host and guest polymers. The duality of supramolecular materials, which possess both switching and self-healing properties, has attracted both supramolecular chemists and materials scientists.

Here, we report supramolecular materials using poly(acrylic acid) $\left(\mathrm{pAA} ; M_{\mathrm{w}}=25 \times 10^{4}\right)$ modified with cyclodextrins $(\mathrm{pAA}-\mathrm{CDs})^{36}$ as a host polymer and pAA with ferrocene (pAA-Fc) as a guest polymer. Ferrocene $(\mathrm{Fc})$ derivatives have attracted attention due to their redox-responsive properties. Variations in the redox potential can induce a reversible sol-gel phase transition in a supramolecular hydrogel formed by pAA- $6 \beta \mathrm{CD}$ and pAA-Fc. Moreover, supramolecular materials formed by host-guest interactions exhibit selfhealing and self-repairing properties.

\section{Results}

Preparation of host and guest polymers. Figure 1 depicts the chemical structures of the host polymers (pAA-CDs) and a guest polymer $(\mathrm{pAA}-\mathrm{Fc})$. $\mathrm{pAA}-\mathrm{CDs}$ were prepared by the reaction of amino-CDs (6-amino- $\alpha \mathrm{CD}$ and 6-amino- $\beta C D$ ) with pAA (Supplementary Fig. S1). According to ${ }^{1} \mathrm{H}$ nuclear magnetic resonance (NMR) spectroscopy, amino-CDs were substituted into $4-5 \%$ of the carboxylic acid groups of pAA (Supplementary Fig. S2 and Supplementary Table S1). These host polymers are called pAA$6 \alpha C D$ and pAA-6 $\beta C D$ for substitutions by 6 -amino- $\alpha C D$ and $6-$ amino- $\beta C D$, respectively. $\mathrm{pAA}-\mathrm{Fc}$ was prepared by the reaction of aminoethylamide Fc with pAA (Supplementary Fig. S3), and Fc was substituted into $2.7 \%$ of the carboxylic acid groups of pAA (Supplementary Fig. S4 and Supplementary Table S1).
Hydrogelation between host and guest polymers. Figure 2 shows photographs of hydrogelation between the host polymers and a guest polymer (2 $\mathrm{wt} \%$ ) in a $\mathrm{pH} 9$ boric acid/KCl/NaOH buffer solution. The $1: 1$ mixture of a $2 \mathrm{wt} \%$ solution of $\mathrm{pAA}-6 \alpha \mathrm{CD} / \mathrm{pAA}-\mathrm{Fc}$, $\mathrm{pAA} / \mathrm{pAA}-6 \beta \mathrm{CD}$ or $\mathrm{pAA} / \mathrm{pAA}-\mathrm{Fc}$ in an aqueous solution had a negligible effect on the viscosity. On the other hand, the mixed solution of pAA- $6 \beta \mathrm{CD} / \mathrm{pAA}-\mathrm{Fc}$ selectively increased the viscosity of the solution to yield a hydrogel (Supplementary Movie 1). These results indicate that not only the host-guest complementarity but also multipoint crosslinks have important roles in forming the supramolecular hydrogel.

Figure 2 shows storage elastic moduli $\left(G^{\prime}\right)$ for pAA- $6 \alpha \mathrm{CD} / \mathrm{pAA}$ Fc, pAA- $6 \beta C D / p A A-F c, p A A / p A A-6 \beta C D$, and pAA/pAA-Fc, pAA$6 \beta C D$, and $\mathrm{pAA}-\mathrm{Fc}(1+1 \mathrm{wt} \%)$ in $\mathrm{pH} 9$ buffer solutions, respectively. Although other samples exhibited $G^{\prime}<50 \mathrm{~Pa}$, pAA-6 $3 \mathrm{CD} / \mathrm{pAA}-\mathrm{Fc}$ had the highest elasticity $(176 \mathrm{~Pa})$, which was more than thrice the value of the comparison cases. 2D NOESY NMR confirmed the interactions between $\beta-C D$ and pAA-Fc (Supplementary Fig. S5) and between the $\beta$-CD moieties of pAA-6 $\beta C D$ and pAA-Fc (Supplementary Fig. S6). Previous studies have suggested that the association constant of $\mathrm{Fc}_{\mathrm{c}}$ in its reduced state for $\beta$ - $\mathrm{CD}$ is larger than that for $\alpha \mathrm{CD}\left(\mathrm{Fc} / \alpha \mathrm{CD} ; K_{\mathrm{a}}=0.14 \times 10^{3} \mathrm{M}^{-1}, \mathrm{Fc} / \beta \mathrm{CD} ; K_{\mathrm{a}}=17 \times 10^{3} \mathrm{M}^{-1}\right)^{37,38}$

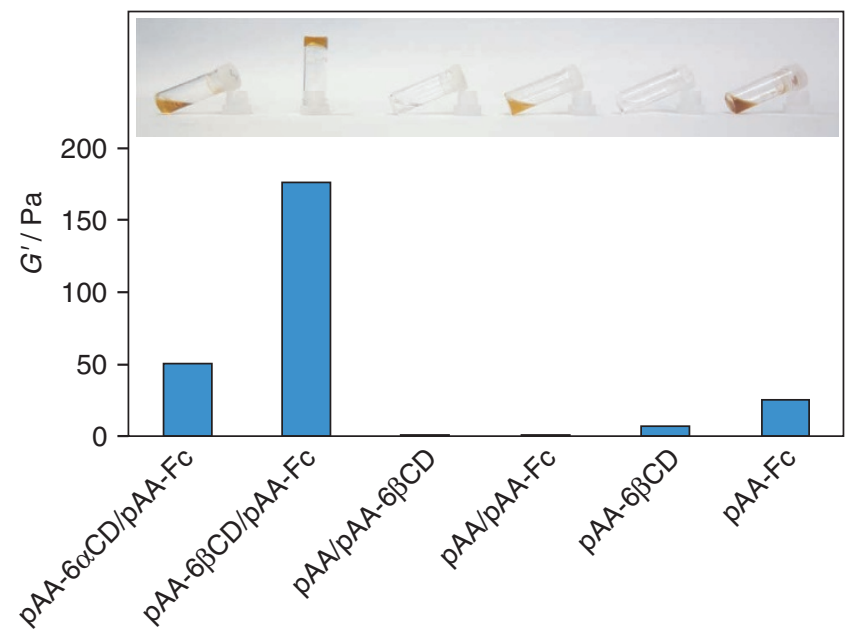

Figure $\mathbf{2}$ | Values of storage elastic modulus. $p A A-6 \alpha C D / p A A-F c, p A A-$ $6 \beta C D / p A A-F c, p A A / p A A-6 \beta C D, p A A / p A A-F c, p A A-6 \beta C D$ and $p A A-F c$ (2wt\%) in a pH 9 buffer solution. Insets are photographs of hydrogelation between host polymers and guest polymers ( $2 \mathrm{wt} \%)$ in aqueous solutions. Although a 1:1 mixture of a solution of $\mathrm{pAA}-6 \alpha \mathrm{CD} / \mathrm{pAA}-\mathrm{Fc}, \mathrm{pAA}-3 \alpha \mathrm{CD}$ / pAA-Fc, pAA-3BCD/pAA-Fc, pAA/pAA-6 $\beta C D$ or pAA/pAA-Fc showed the low viscosity, the mixed solution of $p A A-6 \beta C D / p A A-F c$ selectively increased the viscosity. A hydrogel consisting of $p A A-6 \beta C D / p A A-F c$ is produced by the complementarity between the $\beta-C D$ and $F c$ units.

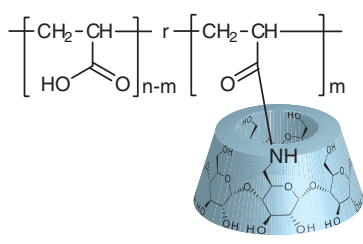

pAA- $6 \alpha C D$

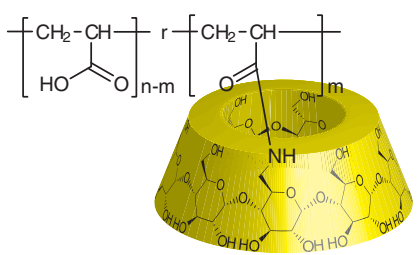

pAA-6ßCD

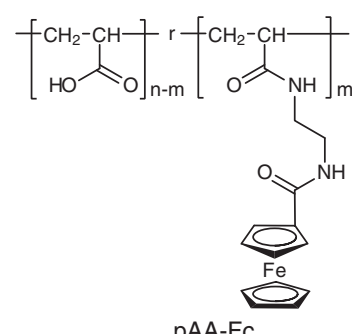

pAA-Fc

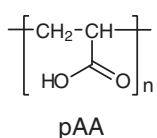

pAA

Figure 1 | Chemical structures of the host polymers and the guest polymer. Host polymers (pAA- $6 \alpha C D$ and $p A A-6 \beta C D$ ), and the guest polymer (pAA-Fc) were synthesized by side-chain modification of $p A A$. 
The $K$ of $\beta$-CD for the Fc group of pAA-Fc was $1.1 \times 10^{3} \mathrm{M}^{-1}$, which is suitable for a competitive host molecule for the Fc group of pAAFc. (Supplementary Figs S7 and S8).

To clarify the complementarity between $\beta-\mathrm{CD}$ and the $\mathrm{Fc}$ groups (reduced state), competitive guest or host molecules were added to the pAA- $6 \beta \mathrm{CD} / \mathrm{pAA}-\mathrm{Fc}$ hydrogel (2wt\%). Adamantane carboxylic acid sodium salt (AdCANa) was used as a competitive guest, because the association constant for $\beta-\mathrm{CD}\left(K_{\mathrm{a}}=35 \times 10^{3} \mathrm{M}^{-1}\right)^{39}$ is higher than that of Fc. Adding AdCANa (10 eq. for the $\beta C D$ group of pAA-6 $6 \mathrm{CD}$ ) into the pAA- $6 \beta \mathrm{CD} / \mathrm{pAA}-\mathrm{Fc}$ hydrogel led to a sharp decrease in the elasticity from $176 \mathrm{~Pa}$ to $23.3 \mathrm{~Pa}$ to form the sol state (Supplementary Fig. S9a). Similarly, adding $\beta$-CD (10 eq. for the Fc group of pAA-Fc) as a competitive host into the $\mathrm{pAA}-6 \beta \mathrm{CD} / \mathrm{pAA}-\mathrm{Fc}$ hydrogel induced a phase transition into the sol state (Supplementary Fig. S9b). They inhibited the formation of an inclusion complex between the $\beta-C D$ unit of pAA- $6 \beta C D$ and the Fc unit of pAA-Fc.

Next, we examined the effects of the host-guest ratio on the elasticity change. The elasticity of pAA- $6 \beta \mathrm{CD} / \mathrm{pAA}-\mathrm{Fc}$ was estimated by varying the ratio of $\mathrm{pAA}-6 \beta \mathrm{CD}$ and $\mathrm{pAA}-\mathrm{Fc}$ in the monomer unit equivalent. Although $\mathrm{pAA}-6 \beta \mathrm{CD} / \mathrm{pAA}-\mathrm{Fc}$ in the non-equivalent ratio demonstrated moderate elasticities, the 1:1 ratio of pAA$6 \beta \mathrm{CD} / \mathrm{pAA}-\mathrm{Fc}$ displayed the largest $G^{\prime}$ value (176 Pa) (Supplementary Fig. S10). These results indicate that a hydrogel consisting of pAA- $6 \beta \mathrm{CD} / \mathrm{pAA}-\mathrm{Fc}$ is produced by the extensive complementarity between the $\beta-C D$ and $\mathrm{Fc}$ units.

Redox-responsive sol-gel switching. We investigated the effect of the redox reagents on the phase transition of the pAA- $6 \beta \mathrm{CD} /$ pAA-Fc hydrogel. We chose $\mathrm{NaClO}$ aq. $(14 \mathrm{mM})$ as an oxidant and glutathione (GSH) as a reductant. Adding $\mathrm{NaClO}$ aq. $(0.1 \mathrm{ml})$ to the pAA- $6 \beta \mathrm{CD} / \mathrm{pAA}-\mathrm{Fc}$ hydrogel $(0.4 \mathrm{ml})$ decreased the viscosity, transforming the hydrogel into the sol. In contrast, continuous addition of GSH $(1.2 \mathrm{mg})$ to the sol recovered the elasticity, reverting it back to the hydrogel (Figure $3 b$ ). $\beta$-CD showed a high affinity for the reduced state of the Fc group due to its hydrophobic nature, whereas the oxidized state of the $\mathrm{Fc}$ group $\left(\mathrm{Fc}^{+}\right)$exhibited a low affinity for $\beta$-CD due to the cationic $\mathrm{Fc}^{+}$group ${ }^{40}$.

Next, we attempted to electrochemically control the pAA$6 \beta \mathrm{CD} / \mathrm{pAA}-\mathrm{Fc}$ hydrogel. The pAA- $6 \beta \mathrm{CD} / \mathrm{pAA}-\mathrm{Fc}$ hydrogel was electrolyzed with a potentiostat using a three-electrode system (platinum plate (working), platinum wire (counter) and $\mathrm{Ag} / \mathrm{AgCl}$ electrode (reference)) and $50 \mathrm{mM}$ of $\mathrm{NaBr}$ as a supporting electrolyte. Electrochemical oxidation of the pAA- $6 \beta \mathrm{CD} / \mathrm{pAA}-\mathrm{Fc}$ hydrogel decreased the elasticity, and consequently transformed the hydrogel into the sol. Subsequent reduction by heating the sol at $50{ }^{\circ} \mathrm{C}$ recovered the elasticity, yielding the hydrogel (Fig. 3c; Supplementary Fig. S11). The redox reactions between $\mathrm{Fc}$ (reduced state) and $\mathrm{Fc}^{+}$ in its oxidized state were tracked by ultraviolet-visible (Supplementary Figs S12-S15) and circular dichroism spectroscopies (Supplementary Fig. S16). A mixture of pAA- $6 \beta C D([\beta C D]=2 \mathrm{mM})$ and $\mathrm{Fc}$ carboxylic acid ( $\mathrm{FcCOOH}, 2 \mathrm{mM}$ ) exhibited a $\mathrm{d}-\mathrm{d}$ transition band around $400-450 \mathrm{~nm}$, but the band disappeared upon oxidation with $\mathrm{NaClO}$ aq. Before oxidizing, the circular dichroism spectra exhibited a negative Cotton band around $400-450 \mathrm{~nm}$, which was assigned to the induced Cotton band between the Fc group and $\beta$ $\mathrm{CD}$ on the side chain of $\mathrm{pAA}-6 \beta \mathrm{CD}$ in an aqueous solution. Adding $\mathrm{NaClO}$ as an oxidant decreased the band, indicating that oxidized $\mathrm{Fc}$ is not included in the cavity of $\beta-\mathrm{CD}$. Consequently, both chemi$\mathrm{cal}$ and electrochemical redox reactions for the pAA- $6 \beta \mathrm{CD} / \mathrm{pAA}-\mathrm{Fc}$ hydrogel yield reversible sol-gel phase transitions.

Self-healing property of $\mathrm{pAA}-6 \beta \mathrm{CD} / \mathrm{pAA}$-Fc hydrogel. We speculated that the pAA- $6 \beta \mathrm{CD} / \mathrm{pAA}-\mathrm{Fc}$ hydrogel would exhibit a selfhealing property because a characteristic feature of the $\mathrm{pAA}-6 \beta \mathrm{CD} /$ pAA-Fc hydrogel is the reversible host-guest interaction between the side chains of both polymers. Thus, we conducted a break test

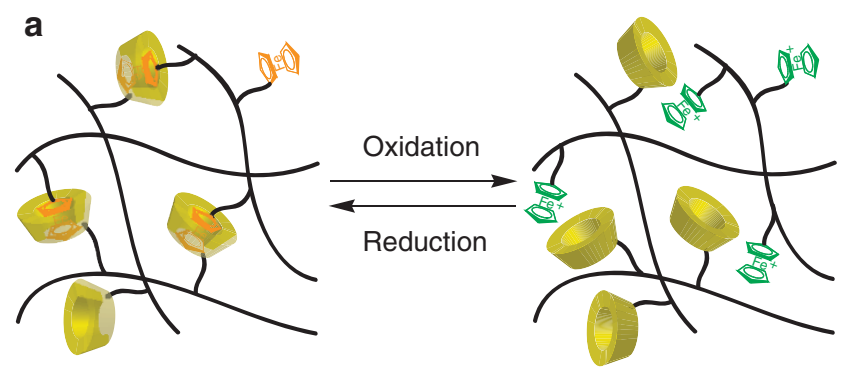

b
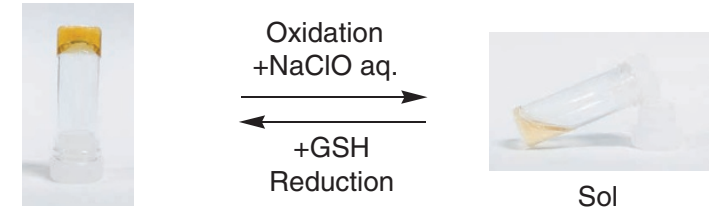

Gel

c
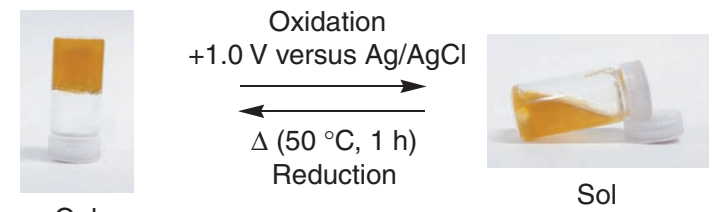

Gel

Sol

Figure $\mathbf{3}$ | Redox-responsive sol-gel transition experiment.

(a) Schematic illustration of sol-gel transition. (b) Sol-gel transition experiment using chemical reagents. Adding $\mathrm{NaClO}$ aq. to the pAA$6 \beta C D / p A A-F c$ hydrogel induced a phase transition into the sol state, and continuous addition of GSH to the sol recovered the elasticity to yield the hydrogel again. (c) Sol-gel transition experiment using electrochemical reactions. Electrochemical oxidation ( $+1.0 \mathrm{~V}$ versus $\mathrm{Ag} / \mathrm{AgCl}$ ) transformed the hydrogel into the sol, whereas reduction recovered the viscosity, reverting it back to the hydrogel.

during continuous step strain measurements. As a precondition of the pAA- $6 \beta C D / p A A-F c$ hydrogel for the break test, we confirmed that the hydrogel did not relax $\left(G^{\prime}>G^{\prime \prime}\right)$ in the frequency range $0.01-100 \mathrm{rad} \cdot \mathrm{s}^{-1}$, which was characterized by dynamic viscoelastic measurements (Supplementary Figs S17 and S18). Supplementary Figure S19 demonstrates that the morphology of the pAA- $6 \beta \mathrm{CD} /$ pAA-Fc hydrogel remained the same for over $72 \mathrm{~h}$.

We measured the rheological property of the pAA- $63 \mathrm{CD} / \mathrm{pAA}-$ Fc hydrogel $(1+1 \mathrm{wt} \%)$ under small $(0.1 \%)$ and large $(200 \%)$ strains (Supplementary Fig. S20). Under a $0.1 \%$ strain, $G^{\prime}$ was larger than $G^{\prime \prime}$, indicating that the pAA- $6 \beta \mathrm{CD} / \mathrm{pAA}-\mathrm{Fc}$ hydrogel formed a selfstanding hydrogel. However, the $G^{\prime}$ and $G^{\prime \prime}$ values were inverted under $200 \%$ strain, indicating that the pAA- $6 \beta \mathrm{CD} / \mathrm{pAA}-\mathrm{Fc}$ hydrogel was converted into the sol state. We assumed that the interaction between the $\beta-\mathrm{CD}$ and $\mathrm{Fc}$ units was cutoff by the $200 \%$ strain in the sol state of pAA- $6 \beta \mathrm{CD} / \mathrm{pAA}-\mathrm{Fc}$. When placed under $0.1 \%$ strain, $G^{\prime}$ and $G^{\prime \prime}$ returned to their original values. $G^{\prime}$ of the pAA- $6 \beta \mathrm{CD} / \mathrm{pAA}$ Fc sol recovered to $90 \%$ of its initial state in $20 \mathrm{~s}$, and the hydrogel was observed in $500 \mathrm{~s}$. This recovery behaviour was repeatable for at least three cycles of varying strains. The reason that the pAA- $6 \beta \mathrm{CD} / \mathrm{pAA}-$ Fc sol transformed to the hydrogel is because the inclusion complex between the $\beta C D$ and $\mathrm{Fc}$ units was reconstructed under $0.1 \%$ strain, suggesting that the characteristic self-healing property of pAA$6 \beta \mathrm{CD} / \mathrm{pAA}-\mathrm{Fc}$ hydrogel is formed by a host-guest interaction.

Macroscopic self-healing of pAA-6 $\beta \mathrm{CD} / \mathrm{pAA}-\mathrm{Fc}$ hydrogel. Based on this rheological property, we confirmed the self-healing ability of the pAA- $6 \beta C D / p A A-F c$ hydrogel. A cube-shaped pAA$6 \beta \mathrm{CD} / \mathrm{pAA}-\mathrm{Fc}$ hydrogel $(1+1 \mathrm{wt} \%)$ was cut in half using a razor 

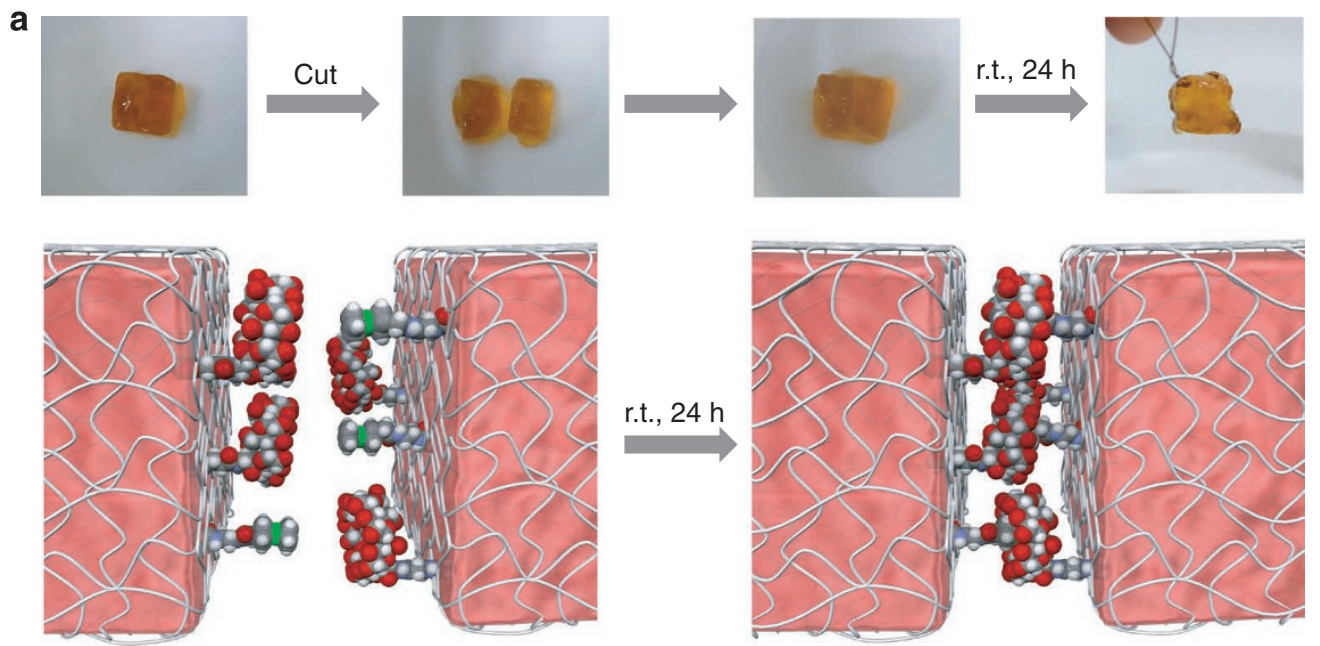

b
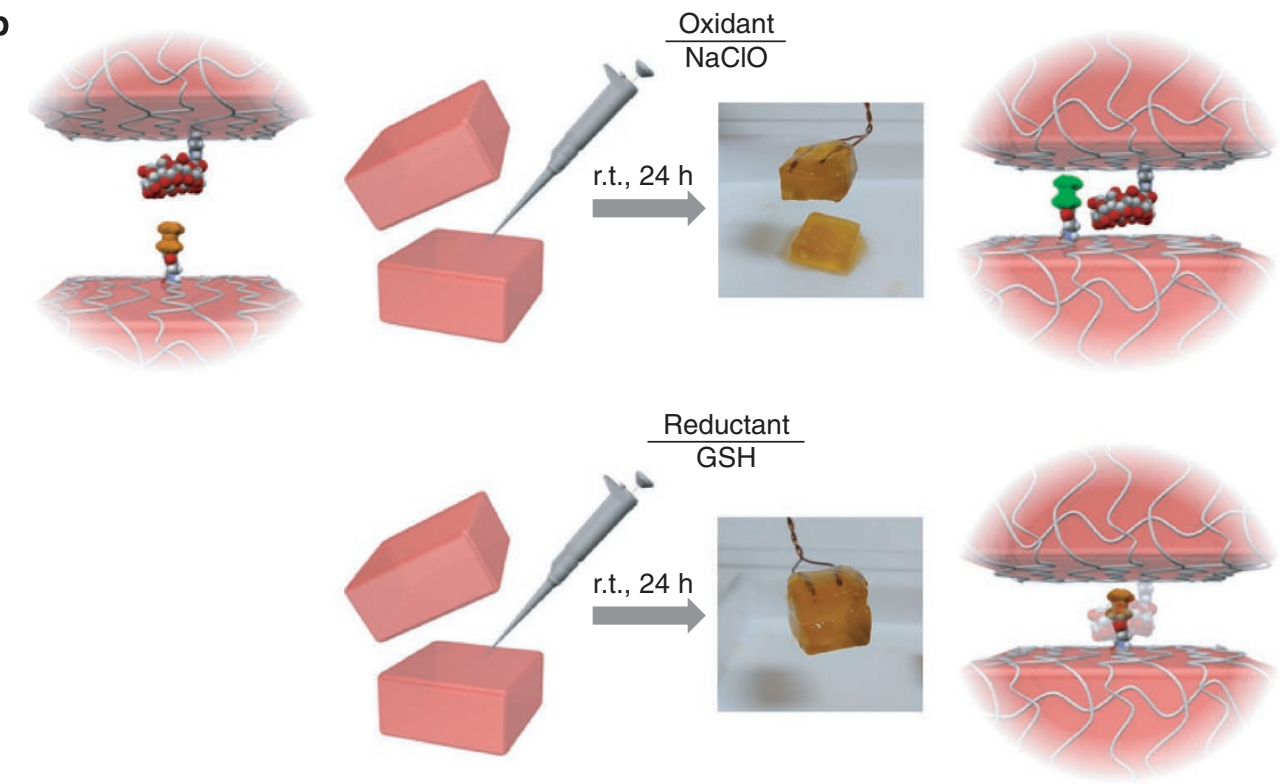

Figure 4 | Self-healing experiments. (a) After standing for $24 \mathrm{~h}$, two cut pAA-6ßCD/pAA-Fc hydrogel ( $1+1 \mathrm{wt} \%$ ) pieces were rejoined, and the crack sufficiently healed to form one gel. (b) Redox-responsive healing experiment of the $p A A-6 \beta C D / p A A-F c$ hydrogel using oxidizing/reducing agents. A pAA-6 $\beta C D / p A A-F c$ hydrogel ( 2 wt\%) was cut in half, and $\mathrm{NaClO}$ aq. was spread on the cut surface. After $24 \mathrm{~h}$, healing was not observed. Re-adhesion was observed $24 \mathrm{~h}$ after spreading GSH aq. onto the oxidized cut surface.

edge, and then rejoined (Fig. $4 \mathrm{a}$ ). After standing for $24 \mathrm{~h}$, the crack disappeared, and the sample hydrogel sufficiently healed to form one gel. To demonstrate the complementary host-guest interaction between the $\beta$-CD and the Fc groups, competitive guest and host molecules were added to the cut plane of the pAA-6 $3 \mathrm{CD} / \mathrm{pAA}-\mathrm{Fc}$ hydrogel (Supplementary Fig. S21). A $3 \mathrm{mM}$ solution of AdCANa as the competitive guest, $\beta$-CD as the competitive host or D-glucose as a reference sample was placed on the cut surfaces, and then the two gels were reattached. After $24 \mathrm{~h}$, the samples with a competitive guest or host did not heal, whereas the sample with D-glucose healed regardless of the amount of D-glucose added. These results indicate that the self-healing property is due to the Fc and $\beta-C D$ moieties, which form an inclusion complex on the cut surfaces of hydrogels. The adhesive strength of the two gels was confirmed by the wedge-shaped strain compression test (Supplementary Fig. S22). After the two gels were rejoined for $24 \mathrm{~h}$, the adhesion strength on the joint surface reached a steady value, indicating that the interaction of the $\mathrm{Fc}$ and $\beta$-CD moieties achieved equilibrium on the surface. The adhesion strength on the joint surface recovered $84 \%$ of the initial gel's strength after $24 \mathrm{~h}$ (Supplementary Fig. S23).
Controlling self-healing ability by redox reaction. Finally, we investigated the control of the self-repairing property of the

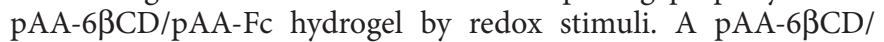
pAA-Fc hydrogel ( $2 \mathrm{wt} \%$ ) was cut in half, and the cut surfaces were coated with an aqueous solution of $\mathrm{NaClO}(7 \mathrm{mM}, 20 \mu \mathrm{l})$. Then the two pieces were reattached according to the experimental operation shown in Figure $4 \mathrm{~b}$. After $24 \mathrm{~h}$, healing was not observed. The $\mathrm{NaClO}$-applied gels did not form an inclusion complex between the $\beta-\mathrm{CD}$ and $\mathrm{Fc}^{+}$units. However, the surface re-adhered after spreading GSH aq. $(20 \mathrm{mM}, 20 \mu \mathrm{l})$, a reducing agent, onto the oxidized cut surface and allowing the gel to stand for $24 \mathrm{~h}$.

\section{Discussion}

We successfully realized reversible sol-gel switching and a selfhealing supramolecular hydrogel system consisting of pAA-6 $3 \mathrm{CD} /$ pAA-Fc. Although microscale switching of supramolecular complexes by redox is well known, a macroscale morphological change is difficult to achieve. This work demonstrates that intelligent supramolecular hydrogels may be formed using a main chain with a sufficient length and an adequate number of guest molecules to 
generate reversible multipoint crosslinks between pAA-6 $3 \mathrm{CD} /$ pAA-Fc. A redox reaction alters the morphology of a supramolecular hydrogel by controlling the formation of an inclusion complex. These stimulus-responsive self-healing properties are similar to the selective cell-adhesive protein observed on a cellular surface. Stimulus-responsive self-healing properties have many general applications. Thus, we believe that these stimulus-responsive and healing properties may eventually be used in stimulus-responsive drug-delivery carriers and peripheral vascular embolization materials with healing properties that target cancer cells and myoma.

\section{Methods}

Materials. Poly(acrylic acid) (pAA, $\left.M_{\mathrm{w}}=250,000\right)$ and $\mathrm{D}_{2} \mathrm{O}$ were obtained from Wako Pure Chemical Industries, Ltd. $\alpha$-Cyclodextrin and $\beta$-cyclodextrin were obtained from Junsei Chemical Co., Ltd. Triethylamine $\left(\mathrm{Et}_{3} \mathrm{~N}\right)$, ethylenediamine, sodium hydroxide, potassium hydroxide, boric acid, potassium chloride and sodium hypochlorite aqueous solution were obtained from Nacalai Tesque Inc. Benzotriazol-1-yl-oxytripyrrolidinophosphonium hexafluorophosphate (РуВОР), 3 -amino-3-deoxy- $\alpha$-cyclodextrin and 3-amino-3-deoxy- $\beta$-cyclodextrin, ferrocenecarboxylic acid, adamantanecarboxylic acid and oxalyl chloride were obtained from Tokyo Kasei Inc. Glutathione was obtained from KOHJIN Co., Ltd. DMSO- $d_{6}$ was obtained from Merck \& Co., Inc. A highly porous synthetic resin (DIAION HP-20) used for column chromatography was purchased from Mitsubishi Chemical Co., Ltd. Dialytic tube $(\mathrm{MWCO}=14,000)$ was purchased from Sanko Junyaku Inc. Water used for the preparation of the aqueous solutions (except for NMR measurements) was purified with a Millipore Elix 5 system (Millipore). Other reagents were used without further purification.

Measurements. The ${ }^{1} \mathrm{H}$ NMR and 2D NMR (NOESY) spectra were recorded at $500 \mathrm{MHz}$ with a JEOL JNM-ECA $500 \mathrm{NMR}$ spectrometer (JEOL). Chemical shifts were referenced to the solvent values ( $\delta=2.49$ p.p.m. for dimethylsulphoxide and $\delta=4.79$ p.p.m. for HOD). The ultraviolet-visible absorption spectra were recorded with a JASCO V-650 and a Hitachi U-4100 spectrometer in water with $1 \mathrm{~cm}$ quartz cell at room temperature. Circular dichroism spectra and ultraviolet-visible spectra were recorded on a JASCO J820 spectrometer in water with $1 \mathrm{~cm}$ quartz cell at room temperature. Dynamic viscoelasticity was measured using an Anton Paar MCR301 rheometer (Anton Paar). Mechanical properties of the gel were measured by the mechanical tension testing system (Rheoner, RE-33005, Yamaden Ltd.).

Preparation and characterization of pAA-CDs. Poly(acrylic acid) $\left(M_{w}=250,000\right)$ was dissolved in $20 \mathrm{ml}$ of $N, N$-dimethylformamide (DMF). To this solution, РyBOP ( 0.06 eq. of acrylic acid unit) and $\mathrm{Et}_{3} \mathrm{~N}$ (0.06 eq. of acrylic acid unit) were added. After stirring for $2 \mathrm{~h}$, a mono-amino-mono-deoxy-CD was added, and the solution was stirred for another $12 \mathrm{~h}$ at room temperature. The polymer product was reprecipitated from $200 \mathrm{ml}$ of ethanol and washed with ethanol. The polymer was dissolved in water, and dialyzed for 12 days with a dialytic tube $(\mathrm{MWCO}=14,000)$. After dialysis, each pAA-CD was obtained by freeze-drying.

pAA-6 $\alpha \mathrm{CD} ;{ }^{1} \mathrm{H}$ NMR $\left(500 \mathrm{MHz}, \mathrm{pD} 9\right.$ buffer, $\left.30^{\circ} \mathrm{C}\right): \delta 1.56$ to $2.12\left(\mathrm{CH}_{2}\right.$ (pAA)), 2.31-2.65 ( $\mathrm{CH}(\mathrm{pAA})), 3.61-3.80\left(\mathrm{C}_{2,4} \mathrm{H}(\mathrm{CD})\right), 3.80-4.11\left(\mathrm{C}_{3,5,6} \mathrm{H}(\mathrm{CD})\right)$, $5.00-5.23\left(\mathrm{C}_{1} \mathrm{H}(\mathrm{CD})\right)$.

pAA-6BCD; ${ }^{1} \mathrm{H}$ NMR $\left(500 \mathrm{MHz}\right.$, pD 9 buffer, $\left.30^{\circ} \mathrm{C}\right): \delta 1.56-2.12\left(\mathrm{CH}_{2}\right.$ (pAA)), 2.31-2.65 ( $\mathrm{CH}(\mathrm{pAA})), 3.61-3.80\left(\mathrm{C}_{2,4} \mathrm{H}(\mathrm{CD})\right), 3.80-4.10\left(\mathrm{C}_{3,5,6} \mathrm{H}(\mathrm{CD})\right)$, $5.05-5.22\left(\mathrm{C}_{1} \mathrm{H}(\mathrm{CD})\right)$

Synthesis and characterization of Fc-CONH-( $\left.\mathrm{CH}_{2}\right)_{2}-\mathrm{NH}_{2}$. Ferrocenecarboxylic acid of $2.00 \mathrm{~g}(8.7 \mathrm{mmol})$ was suspended in $120 \mathrm{ml}$ of dichloromethane (DCM). Then $2 \mathrm{ml}(23.3 \mathrm{mmol}, 2.7 \mathrm{eq}$.) of oxalyl chloride was added dropwise, and the suspension was stirred for $3 \mathrm{~h}$ at room temperature. The orange suspension turned into a red solution. After evaporating the solvent, ferrocenecarboxyl chloride (red solid) was dissolved in $60 \mathrm{ml}$ of DCM. A volume of $6 \mathrm{ml}(89.9 \mathrm{mmol}, 10 \mathrm{eq}$.$) of$ ethylenediamine was dissolved in $60 \mathrm{ml}$ of DCM, and the ferrocenecarboxyl chloride solution was added dropwise. After stirring overnight at room temperature, the solution was washed with $80 \mathrm{ml}$ of $10 \% \mathrm{KOH}$ aq., and the DCM layer was collected and evaporated. The orange solid was washed with $300 \mathrm{ml}$ of hexane: ethyl acetate $=9: 1$, and the solid product was collected via a centrifuge and dried for 4 days at $50{ }^{\circ} \mathrm{C}$ to obtain Fc-CONH- $\left(\mathrm{CH}_{2}\right)_{2}-\mathrm{NH}_{2}$ as a yellow powder in $83 \%$ yield.

${ }^{1} \mathrm{H}$ NMR $\left(500 \mathrm{MHz}, \mathrm{D}_{2} \mathrm{O}, 30^{\circ} \mathrm{C}\right): \delta 2.90\left(2 \mathrm{H}, \mathrm{t}, \mathrm{Fc}-\mathrm{CONH}-\mathrm{CH}_{2}-\mathrm{CH}_{2}-\mathrm{NH}_{2}\right), 3.46$ $\left(2 \mathrm{H}, \mathrm{t}, \mathrm{Fc}-\mathrm{CONH}-\mathrm{CH}_{2}-\mathrm{CH}_{2}-\mathrm{NH}_{2}\right), 4.36(5 \mathrm{H}, \mathrm{s}, \mathrm{Cp}), 4.61(2 \mathrm{H}, \mathrm{t}, \mathrm{Cp}), 4.89(2 \mathrm{H}, \mathrm{t}, \mathrm{Cp})$.

Synthesis and characterization of pAA-Fc. PyBOP $(0.22 \mathrm{~g}, 0.42 \mathrm{mmol}, 0.06 \mathrm{eq}$. of acrylic acid unit) was added to a $40 \mathrm{ml}$ DMF solution of pAA $\left(M_{\mathrm{av}}=250,000\right.$, $500.3 \mathrm{mg})$. In all, $0.95 \mathrm{~g}(0.35 \mathrm{mmol}, 0.05$ eq. of acrylic acid unit) of Fc-CONH$\left(\mathrm{CH}_{2}\right)_{2}-\mathrm{NH}_{2}$ was dissolved in $10 \mathrm{ml}$ of DMF, and $0.06 \mathrm{ml}(0.43 \mathrm{mmol}$, 0.06 eq. of acrylic acid unit) of $\mathrm{Et}_{3} \mathrm{~N}$ was added. This solution was added dropwise to the pAA solution and stirred for $12 \mathrm{~h}$ at room temperature. After stirring, the solution was diluted with water and dialyzed in water for 7 days with dialytic tube $(\mathrm{MWCO}=14,000)$. After dialysis, pAA-Fc was obtained by freeze-drying.
${ }^{1} \mathrm{H}$ NMR (500 MHz, pD 9 buffer, $\left.30^{\circ} \mathrm{C}\right): \delta 1.40-1.91\left(\mathrm{CH}_{2}\right.$ (pAA)), 2.05-2.50 (CH (pAA)), 4.37 (s, Cp), 4.61 (s, Cp), 4.91 (s, Cp (overlapped with HOD)).

Breaking stress measurement of the pAA-6 $\beta C D / p A A-F c$ hydrogel. One centimetre cube-shaped pAA- $6 \beta \mathrm{CD} / \mathrm{pAA}-\mathrm{Fc}$ hydrogel $(3 \mathrm{wt} \%)$ was cut in half using a razor edge, and then rejoined at $24^{\circ} \mathrm{C}$ (waiting time $<5 \mathrm{~min}$.). After standing for $24 \mathrm{~h}$, the breaking stress was measured by a creep metre with a wedge-shaped plunger (Supplementary Figs S22 and S23).

\section{References}

1. Dry, C. M. Smart building materials which prevent damage and repair themselves, in smart materials fabrication and materials for micro-electro-mechanical systems Symposium held April 28-30, 1992, San Francisco, CA, vol. 276 in series Materials Research Society Proceedings, MRS Philadelphia, PA 331, (1992).

2. White, S. R. et al. Autonomic healing of polymer composites. Nature 409, 794-797 (2001)

3. Chen, X. X. et al. Thermally re-mendable cross-linked polymeric material. Science 295, 1698-1702 (2002).

4. Toohey, K. S., Sottos, N. R., Lewis, J. A., Moore, J. S. \& White, S. R. Self-healing materials with microvascular networks. Nat. Mater. 6, 581-585 (2007).

5. Cordier1, P., Tournilhac, F., Soulié-Ziakovic, C. \& Leibler, L. Self-healing and thermoreversible rubber from supramolecular assembly. Nature 451, 977-980 (2008).

6. Bergman, S. D. \& Wudl, F. Mendable polymers. J. Mater. Chem. 18, 41-62 (2008)

7. Wool, R. P. Self-healing materials: a review. Soft Matter 4, 400-418 (2008).

8. Wang, Q. et al. High-water-content mouldable hydrogels by mixing clay and a dendritic molecular binder. Nature 463, 339-343 (2010).

9. Burnworth, M. et al. Optically healable supramolecular polymers. Nature 472, 334-338 (2011)

10. Lyshevski, S. E. Nano-and Micro-Electromechanical Systems:Fundamentals of Nano- and Microengineering (CRC, 2005)

11. Ozin, G. A., Manners, I., Fournier-Bidoz, S. \& Arsenault, A. Dream nanomachines. Adv. Mater. 17, 3011-3018 (2005).

12. Liu, C. Foundations of MEMS (Pearson Education, 2006)

13. Huang, T. J. et al. A nanomechanical device based on linear molecular motors. Appl. Phys. Lett. 85, 5391-5393 (2004).

14. Anquetil, P. A., Yu, H. H., Madden, J. D., Swager, T. M. \& Hunter, I. W. Recent advances in thiophene-based molecular actuators. Proc. SPIE Int. Soc. Opt. Eng. 5051, 42-53 (2003)

15. Collin, J.- P., Dietrich-Buchecker, C., Gaviña, P., Jiménez-Molero, M. C. \& Sauvage, J.- P. Shuttlesand muscles: linear molecular machines based on transition metals. Acc. Chem. Res. 34, 477-487 (2001).

16. Juluri, B. K. et al. Mechanical actuator driven electrochemically by artificial molecular muscles. ACS Nano. 3, 291-300 (2009).

17. Eddington, D. T. \& David, J. B. Flow control with hydrogels. Adv. Drug. Deliv. Rev. 56, 199-210 (2004).

18. Itoga, K., Yamato, M., Kobayashi, J., Kikuchi, A. \& Okano, T. Cell micropatterning using photopolymerization with a liquid crystal device commercial projector. Biomaterials 25, 2047-2053 (2004).

19. Piepenbrock, M. M., Lloyd, G. O., Clarke, N. \& Steed, J. W. Metal- and anionbinding supramolecular gels. Chem. Rev. 110, 1960-2004 (2010).

20. Jeong, B., Kim, S. W. \& Bae, Y. H. Thermosensitive sol-gel reversible hydrogels. Adv. Drug Deliv. Rev. 54, 37-51 (2002).

21. Yoshida, R. Self-oscillating gels driven by the Belousov-Zhabotinsky reaction as novel smart materials. Adv. Mater. 22, 3463-3483 (2010).

22. Murata, K. et al. Thermal and light control of the sol-gel phase transition in cholesterol-based organic gels. Novel helical aggregation modes as detected by circular dichroism and electron microscopic observation. J. Am. Chem. Soc. 116, 6664-6676 (1994).

23. Jung, J. H., Ono, Y. \& Shinkai, S. Sol-gel polycondensation of tetraethoxysilane in a cholesterol-based organogel system results in chiral spiral silica. Angew. Chem. Int. Ed. 39, 1862-1865 (2000).

24. Lee, C. T. Jr., Smith, K. A. \& Hatton, T. A. Photoreversible viscosity changes and gelation in mixtures of hydrophobically modified polyelectrolytes and photosensitive surfactants. Macromolecules 37, 5397-5405 (2004).

25. Tomatsu, I., Hashidzume, A. \& Harada, A. Contrast viscosity changes upon photoirradiation for mixtures of poly(acrylic acid)-based $\alpha$-cyclodextrin and azobenzene polymers. J. Am. Chem. Soc. 128, 2226-2227 (2006).

26. Ahmed, S. A. et al. Multiaddressable self-assembling organogelators based on 2H-chromene and N-acyl-1,ù-amino acid units. Langmuir. 18, 7096-7101 (2002).

27. Kawano, S., Fujita, N. \& Shinkai, S. A coordination gelator that shows a reversible chromatic change and solgel phase-transition behavior upon oxidative/reductive stimuli. J. Am. Chem. Soc. 126, 8592-8593 (2004).

28. Tsuchiya, K. et al. Control of viscoelasticity using redox reaction. J. Am. Chem. Soc. 126, 12282-12283 (2004)

29. Hempenius, M. A., Cirmi, C., Song, J. \& Vancso, G. J. Synthesis of poly(ferrocenylsilane) polyelectrolyte hydrogels with redox controlled swelling. Macromolecules 42, 2324-2326 (2009). 
30. Zuoab, F., Luoab, C., Dinga, X., Zhenga, Z., Chenga, X. \& Penga, Y. Redoxresponsive inclusion complexation between $\beta$-cyclodextrin and ferrocenefunctionalized poly(N-isopropylacrylamide) and its effect on the solution properties of this polymer. Supramol. Chem. 20, 559-564 (2008).

31. Ritter, H., Mondrzik, B. E., Rehahn, M. \& Gallei, M. Free radical homopolymerization of a vinylferrocene/cyclodextrin complex in water. Beilstein J. Org. Chem. 6: No. 60 (2010).

32. Tomatsu, I., Hashidzume, A. \& Harada, A. Redox-responsive hydrogel system using the molecular recognition of $\beta$-cyclodextrin. Macromol. Rapid Commun 27, 238-241 (2006).

33. Tamesue, S., Takashima, Y., Yamaguchi, H., Shinkai, S. \& Harada, A. Photoswitchable supramolecular hydrogels formed by cyclodextrins and azobenzene polymers. Angew. Chem. Int. Ed. 122, 7623-7626 (2010).

34. Deng, W., Yamaguchi, H., Takashima, Y. \& Harada, A. A chemical-responsive supramolecular hydrogel from modified cyclodextrins. Angew. Chem. Int. Ed. 46, 5144-5147 (2007).

35. Ogoshi, T., Takashima, Y., Yamaguchi, H. \& Harada, A. Chemically-responsive solgel transition of supramolecular single-walled carbon nanotubes (SWNTs) hydrogel made by hybrids of SWNTs and cyclodextrins. J. Am. Chem. Soc. 129, 4878-4879 (2007).

36. Guo, X., Abdala, A. A., May, B. L., Lincoln, S. F., Khan, S. A. \& Prud'homme, R. K. Novel associative polymer networks based on cyclodextrin inclusion compounds. Macromolecules 38, 3037-3040 (2005).

37. Harada, A. \& Takahashi, S. Preparation and properties of cyclodextrin inclusion compounds of organometallic complexes. Ferrocene inclusion compounds. J. Incl. Phenom. 2, 791-798 (1984).

38. Wu, J.- S., Toda, K., Tanaka, A. \& Sanemasa, I. Association constants of ferrocene with cyclodextrins in aqueous medium determined by solubility measurements of ferrocene. Bull. Chem. Soc. Jpn. 71, 1615-1618 (1998).

39. Rekharsky, M. V. \& Inoue, Y. Complexation thermodynamics of cyclodextrins. Chem. Rev. 98, 1875-1917 (1998).
40. Moozyckine, A. U., Bookham, J. L., Deary, M. E. \& Davies, D. M. Structure and stability of cyclodextrin inclusion complexes with the ferrocenium cation in aqueous solution: 1H NMR studies. J. Chem. Soc., Perkin Trans. 2, 1858-1862 (2001).

\section{Acknowledgements}

We thank Mr. S. Adachi (Osaka University) for his support with the 2D-NMR experiments. This work was financially supported by the 'Core Research for Evolutional Science and Technology' program of the Japan Science and Technology Agency, Japan.

\section{Author contributions}

M.N. performed syntheses, characterizations and spectroscopic studies. Y.T. conceived and directed the study, contributed to all experiments and wrote the paper. H.Y. supported characterizations. A.H. oversaw the project as well as contributed to the execution of the experiments and interpretation of the results.

\section{Additional information}

Supplementary Information accompanies this paper at http://www.nature.com/ naturecommunications

Competing financial interests: The authors declare no competing financial interests.

Reprints and permission information is available online at http://npg.nature.com/ reprintsandpermissions/

How to cite this article: Nakahata, M. et al. Redox responsive self-healing materials formed from host-guest polymers. Nat. Commun. 2:511 doi: 10.1038/ncomms1521 (2011).

License: This work is licensed under a Creative Commons Attribution-NonCommercialShare Alike 3.0 Unported License. To view a copy of this license, visit http:// creativecommons.org/licenses/by-nc-sa/3.0/ 